\title{
Maternal Outcome of Cases of Placenta Previa with and without Morbidly Adherent Placenta at King Abdul-Aziz University Hospital, Saudi Arabia
}

\author{
Ashraf Radwan', Abdel Magid Abdou1, Sausan Kafy², Mamdouh Sheba1, Hassan Allam 1*, \\ Moaz Bokhari' ${ }^{1}$, Majed Almutairi' ${ }^{1}$ \\ ${ }^{1}$ Department of Obstetrics and Gynecology, King Abdul-Aziz University, Rabigh Branch, Rabigh, KSA \\ ${ }^{2}$ Department of Obstetrics and Gynecology, King Abdul-Aziz University Hospital, Jeddah, KSA \\ Email: ^hallam@kau.edu.Sa
}

How to cite this paper: Radwan, A., Abdou, A.M., Kafy, S., Sheba, M., Allam, H., Bokhari, M. and Almutairi, M. (2018) Maternal Outcome of Cases of Placenta Previa with and without Morbidly Adherent Placenta at King Abdul-Aziz University Hospital, Saudi Arabia. Open Journal of Obstetrics and Gynecology, 8, 1414-1422. https://doi.org/10.4236/ojog.2018.813142

Received: October 18, 2018

Accepted: November 9, 2018

Published: November 12, 2018

Copyright $\odot 2018$ by authors and Scientific Research Publishing Inc. This work is licensed under the Creative Commons Attribution International License (CC BY 4.0).

http://creativecommons.org/licenses/by/4.0/

\section{(c) (i) Open Access}

\begin{abstract}
Introduction: Worldwide increasing cesarean section rates are expected to have a parallel increase in the number of cases of Placenta Previa with all the expected complications, including pathologically adherent placenta. This morbidly adherent placenta constitutes a serious and possibly a life threatening complication. An efficient team capable for managing possible complicated situations will be able to reduce mortality and morbidity. Objectives: The aim of our study was to evaluate maternal outcome in cases of Placenta Previa with and without morbidly adherent placenta. Methods: Analysis of all pregnancies complicated by antepartum hemorrhage during the period from January 2013 to September 2017 at King Abdul-Aziz University Hospital (KAUH), Jeddah, Kingdom of Saudi Arabia (KSA) was done. Cases of Placenta Previa with gestational age $>28$ weeks were included. They were classified into 2 groups; Group (A) included Placenta Previa cases without morbidly adherent placenta and Group (B) included cases with morbidly adherent placenta. Maternal outcomes were recorded. Results: Placenta Previa was the leading cause of antepartum hemorrhage constituting $76.8 \%$, out of them $52 \%$ were unbooked. Morbidly adherent placenta constituted $13.5 \%$ of total Placenta Previa cases and was diagnosed prenatally in only 1 case. Morbidity rate in placenta previa patients with adherent placenta (Group B) was higher than in placenta previa without adherent placenta (Group A). We considered the occurrence of intrapartum hypovolemic shock, Intensive care unit admission, surgical complications and peripartum hysterectomy as parameters for morbidity. $\mathrm{P}$ value for hypovolemic shock was insignificant $(\mathrm{P}=$
\end{abstract}


0.580), significant for Intensive care unit admission $(P=0.008)$, significant for surgical complications $(\mathrm{P}=0.009)$ and significant for peripartum hysterectomy $(P \leq 0.001)$. Conclusion: Morbidity rates are significantly higher in cases with morbidly adherent placenta. Although we had a low prenatal detection rate, the presence of multidisciplinary team and an available blood bank counteracted the diagnostic pitfalls. Further multicenter studies are recommended.

\section{Keywords}

Maternal Outcomes, Placenta Previa, With and without Adherent Placenta

\section{Introduction}

Maternal and fetal mortality and morbidity due to Placenta Previa are considerable, and constitute too much burden on health care resources [1]. Worldwide increasing cesarean section rates are expected to have a parallel increase in the number of cases of Placenta Previa with all the expected complications, including pathologically adherent placenta. Decidual deficiency at the scar area is believed to be the contributing factor. This morbidly adherent placenta, with the various grades of severity according to depth of penetration, constitutes a serious and possibly a life threatening complication during pregnancy. It could present with massive intrapartum hemorrhage either spontaneously or during trials to separate the placenta during caesarian section [2] [3].

Surgical interference in these cases requires a competent multidisciplinary team including urologist, vascular surgeon and possibly interventional radiologist for possible selective artery embolization. An efficient team capable for managing possible complicated situations will reduce mortality and morbidity to the least possible [1] [4]. This is comparable to a previous review in King Abdul-Aziz University Hospital analyzing placenta previa cases from the period 2001 to 2013, reported $11.3 \%$ hypovolemic shock with massive blood transfusion, admission to I.C.U and $6.5 \%$ hysterectomy. Their cases were $82 \%$ unbooked patients compared to $52 \%$ in our study.

\section{Patients and Methods}

The Ethical approval to conduct this work was obtained from the research ethical committee of King Abdul-Aziz University. The hospital records of all pregnancies complicated by antepartum hemorrhage during the period from January 2013to September 2017 among Saudi patients at KAUH, Jeddah, KSA, were obtained and analyzed. Cases of Placenta Previa with gestational age $>28$ weeks were included. They were classified according to the reported surgical findings into 2 groups. Group (A) included Placenta Previa without morbidly adherent placenta and Group (B) including Placenta Previa with morbidly adherent pla- 
centa regardless of its type; Accreta, Increta or Percreta. Maternal outcomes we rerecorded. Results were analyzed and statistically evaluated by SPSS version 20 . Significant $\mathrm{P}$ value $<0.05$ by chi square test.

Our exclusions criteria in this study were:

- Any patients presented with bleeding before 28 weeks.

- Antepartum hemorrhage's Patients diagnosed as accidental hemorrhage, hx of trauma or coagulopathy disorder.

Our variables used for the comparison between group A and group B were Age, Parity, Booking status, Previous c/s and Maternal outcomes (Hypovolemic shock, DIC, admission to ICU, surgical complication and Peripartum hysterectomy).

\section{Results}

Total deliveries during the study period were 6000. Antepartum hemorrhage cases were 125 patients constituting $2.1 \%$ of admitted cases. Incidence of antepartum hemorrhage was 20.8/1000 live birth. Out of these cases, placenta Previa was the leading cause constituting $76.8 \%$ of antepartum hemorrhage cases $(16 / 1000$ live births). Cases with placenta Previa as a cause of antepartum hemorrhage were 96 constituting $76.8 \%$ of antepartum hemorrhage cases and $1.6 \%$ of total admissions during the study period. Cases with morbidly adherent placenta were 11 constituting $11.45 \%$ of placenta Previa cases, $8.8 \%$ of antepartum hemorrhage cases and $0.2 \%$ of total admissions. Only 1 out of 11 cases (9\%) with morbidly adherent placenta were diagnosed preoperatively by an advanced ultrasound and Magnetic Resonance Imaging (MRI) and the rest were discovered accidently during caesarian section.

The mean age of all patients was $32.3 \pm 5.1$ years with a range of $20-44$. There was no significant association between the age and the causes of antepartum hemorrhage $(\mathrm{APH})(\mathrm{P}=0.278)$ (Figure 1$)$. The mean parity of all patients was $3.0 \pm 1.5$. There was no significant relation between the causes of APH and the parity $(P=0.119)$. Cases with previous caesarian section constituted $75.4 \%$, (Figure 2). A mean cesarean section rate of $2.21 \pm 0.137$ with a minimum of 1 previous section and a maximum of previous 8 . The relationship between the previous cesarean section and causes of APH was statistically significant $(\mathrm{P}=$ less than 0.05) (Figure 2). Booked patients of group (A) were 52 and group B (9). While unbooked patients were 33 from group (A) and 2 patients from group (B). The association between the booking status and the cause of APH was statistically significant $(\mathrm{P}=0.013)$.

Our cases were $52 \%$ booked patients and $48 \%$ unbooked, first seen during labor or emergency bleeding (Figure 2). Maternal outcome was analyzed regarding mortality and morbidity related to diagnosis. No mortality was recorded during the study period due to antepartum hemorrhage. As regards morbidity, we considered the occurrence of intra partum hypovolemic shock, surgical complications e.g. urologic injuries, peripartum hysterectomy or need for postnatal 


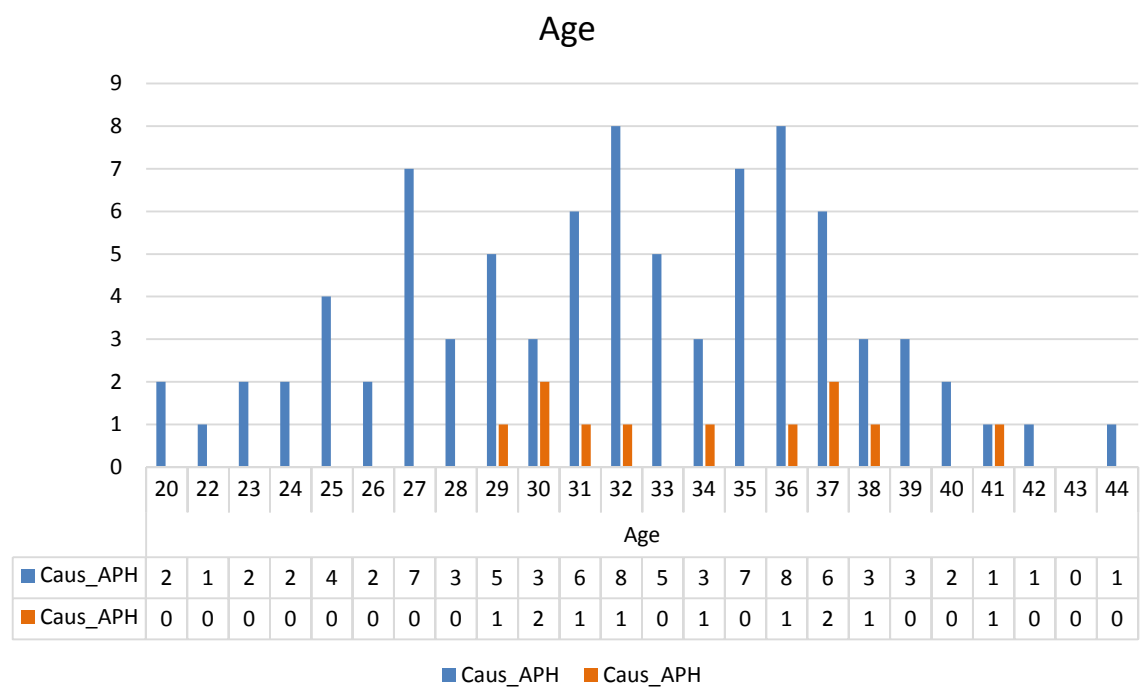

Figure 1. Represent the age of the patient between two groups age $(\mathrm{P}$ value $=0.278)$.

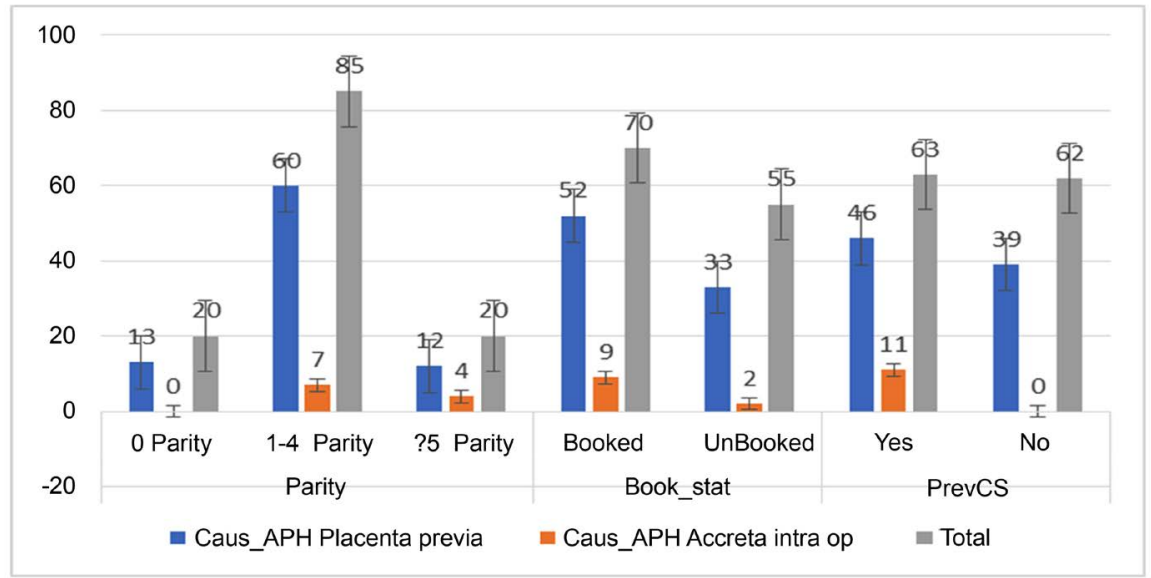

Figure 2. Correlation between parity, booked patient, previous C.S and cause of APH. Parity $(\mathrm{P}$ value $=0.119)$, Booking status $(\mathrm{P}$ value $=0.580)$ and previous $\mathrm{C} / \mathrm{s}(\mathrm{P}$ value $=$ $0.00)$.

admission to intensive care as parameters for morbidity. Collectively, 36 patients out of 96 placenta Previa patients have morbidity compilations. Total number of patients who had hypovolemic shock was 7 patients. 5 of them from the patients had Placenta Previa without adherent placenta (group A). 2 of them were from the patients who had Placenta Previa with morbidly adherent placenta (group B). The P value was 0.580 indicating no statistical significance (Figure 3). DIC was not reported in all cases involved in the study (Figure 3). For ICU Admission, 4 patients were admitted to ICU In group (A), while 3 patients from group (B). The association between ICU admission following postpartum hemorrhage in group B was statistically significant compared to cases of group A P $=0.008$. This supports the relationship between the causes of APH and the ICU Admission (Figure 3). Out of 85 patients who were diagnosed with placenta previa without adherent placenta, 5 patients had surgical complications. Out of the 11 


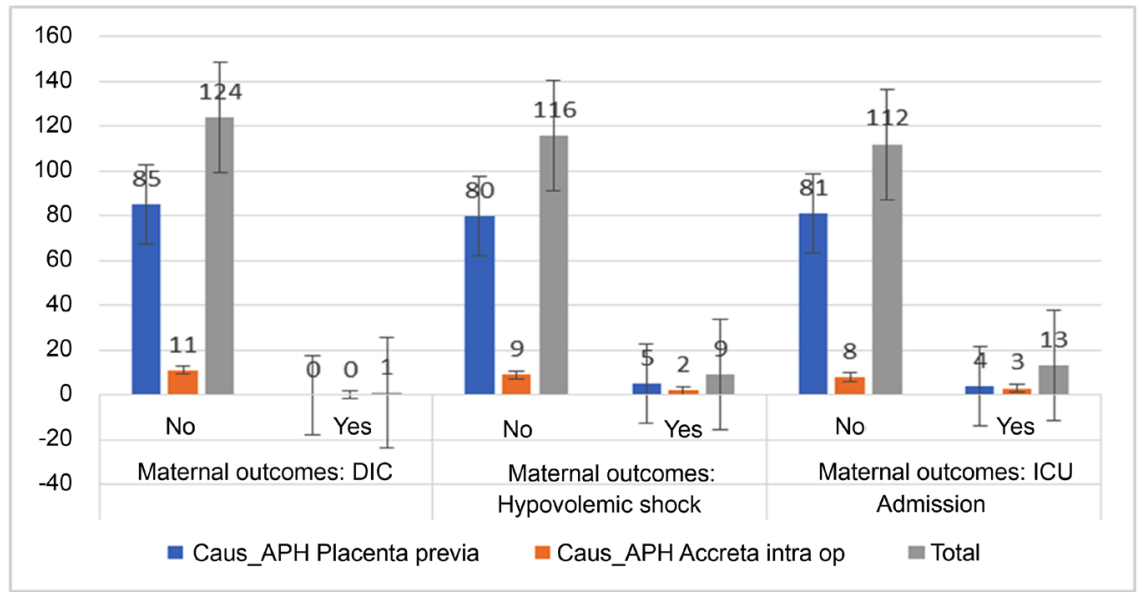

Figure 3. Correlation between DIC, hypovolemic shock, ICU admission and cause of APH. DIC $(\mathrm{P}$ value $=0.317)$, Hypovolemic shock $(\mathrm{P}$ value $=0.580), \mathrm{ICU}$ admission $(\mathrm{P}$ value $=0.008)$.

patients diagnosed with placenta previa with adherent placenta, 4 had surgical complications $(\mathrm{P}=0.009)$. This indicates a relationship between the causes of APH and Surgical complications (Figure 4). Thirteen patients had Peripartum hysterectomy, 6 of them from group (A) and the rest from group (B). The relation between the Causes of APH and Peripartum hysterectomy was statistically significant $(\mathrm{P}<0.0001)$ (Figure 4).

Comparison of the cases of placenta Previa with the cases of placenta previa with morbidly adherent placenta, revealed that morbidity rates were higher in cases with morbidly adherent placenta than cases with placenta Previa only. The difference between the two groups was statistically significant $(\mathrm{P}<0.001)$ (Table $1)$.

Only one case from the morbidly adherent placenta Previa cases, was diagnosed preoperatively by more professional ultrasound and confirmed by MRI (9\%). Other cases were just diagnosed as placenta Previa by basic ultrasound and discovered accidently during caesarean section to be accreta, increta or percreta. Interestingly, revising this one previously diagnosed case, one of them went morbidly free but the other case had intraoperative hypovolemic shock, accidental bladder injury and postoperative admission to intensive care. Due to the small sample size, no statistical conclusion could be obtained.

\section{Discussion}

Antepartum hemorrhage constitutes a major cause of maternal and fetal mortality and morbidity. In the existing study, the incidence of antepartum hemorrhage was 20.8/1000 live births. Out of these cases, placenta Previa was the leading cause constituting $76.8 \%$ of antepartum hemorrhage cases (16/1000 live births). Some studies agreed with our finding and in others, placental abruption was the leading cause [5]. The incidence of placenta Previa in our study was much higher than reported before. In a meta-analysis report in 2003, overall 


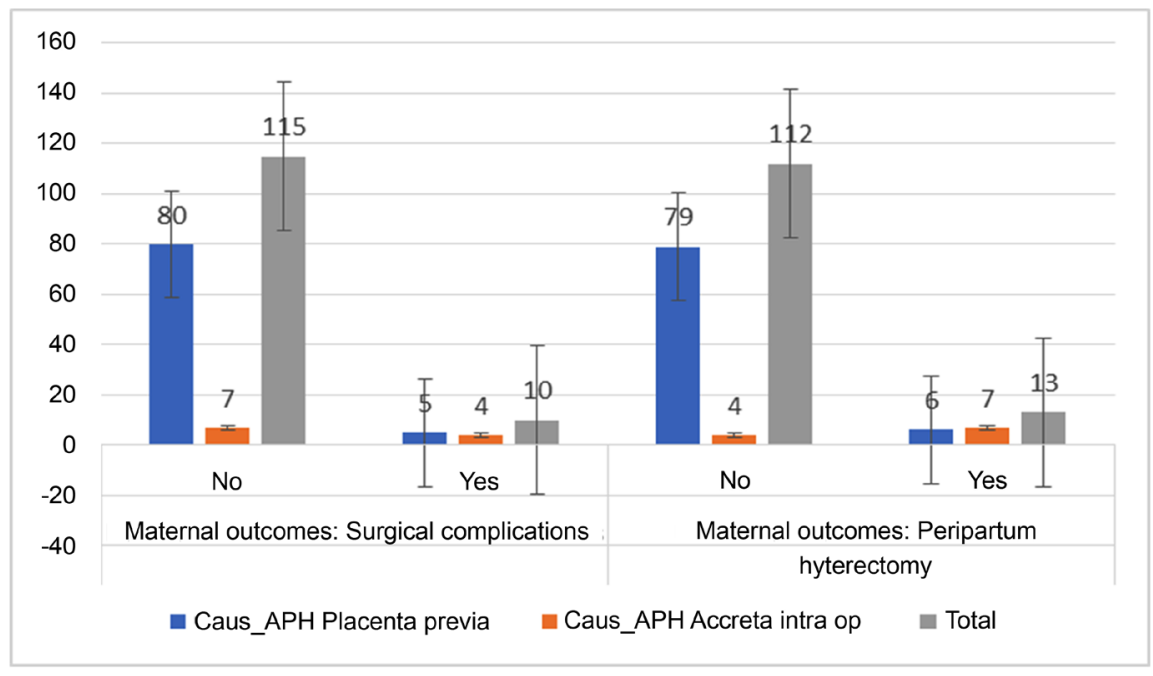

Figure 4. Correlation between surgical complications, hysterectomy and cause of APH. Surgical complications $(\mathrm{P}$ value $=0.009)$, peripartum hysterectomy $(\mathrm{P}$ value $=0.00)$.

Table 1. Comparison of maternal morbidity rates between cases of placenta previa with and without adherent placenta.

\begin{tabular}{|c|c|c|c|c|c|}
\hline \multirow[t]{2}{*}{ Morbidity } & \multicolumn{2}{|c|}{$\begin{array}{c}\text { Group A } \\
\text { Placenta previa without } \\
\text { adherent placenta }\end{array}$} & \multicolumn{2}{|c|}{$\begin{array}{c}\text { Group B } \\
\text { Placenta previa with morbidly } \\
\text { adherent placenta }\end{array}$} & \multirow[t]{2}{*}{$P$ value } \\
\hline & $\mathbf{N}$ & $\%$ & $\mathrm{~N}$ & $\%$ & \\
\hline & (85 cases) & $88.54 \%$ & (11 cases) & (11.46\%) & \\
\hline $\begin{array}{l}\text { Hypovolemic } \\
\text { shock }\end{array}$ & 5 & $(5.88 \%)$ & 2 & $(18.2 \%)$ & 0.580 \\
\hline ICU admission & 4 & $(4.7 \%)$ & 3 & $(27.3 \%)$ & 0.008 \\
\hline $\begin{array}{c}\text { Surgical } \\
\text { complications }\end{array}$ & 5 & $(5.88 \%)$ & 4 & $(36.4 \%)$ & 0.009 \\
\hline $\begin{array}{c}\text { Peripartum } \\
\text { hysterectomy }\end{array}$ & 6 & $(7 \%)$ & 7 & $(63.6 \%)$ & $<0.001$ \\
\hline
\end{tabular}

${ }^{*}$ Significance at $\mathrm{P}$ value $<0.05$, using Chi-square Test.

prevalence rate of placenta Previa was 4.0/1000 live births [6]. This increased incidence in placenta Previa cases in our study is expected and parallel with the progressive increase in caesarian section rates and number of referred cases from other hospitals and clinics to King Abdul-Aziz University Hospital which is a tertiary care hospital. This also can be explained by the fact that placenta Previa is a leading cause for antepartum hemorrhage as these cases are more commonly to be diagnosed early and referred from other centers and hospitals electively more than accidental hemorrhage that can occur suddenly and unpredictably giving little time for referral.

In the present study, morbidity rates for all reported cases of placenta previa were $37.5 \%$. This is comparable to a previous review in King Abdul-Aziz University Hospital analyzing Placenta Previa cases from the period 2001 To 2013. 
They reported $11.3 \%$ cases of hypovolemic shock with massive blood transfusion and admission to the intensive care unit (ICU) and 6.5\% cases of hysterectomy. Their cases were $82 \%$ unbooked patients compared to $48 \%$ in our study [7].

Although it is considered a rare pathology, there is a worldwide increased incidence of morbidly adherent placenta due to increasing caesarian section rates. In our study, morbidly adherent placenta was encountered in $11.46 \%$ of placenta Previa cases. This is comparable with other studies that revised 64,359 deliveries over 20 years and reported an overall incidence of placenta accreta to be 1 in 533 live births [8]. Another study analyzing placenta Previa cases in 10 Austrian hospitals between 1993 and 2012 reported concomitant adherent placenta to be present in only $4 \%$ [9].

It is well known that cases with morbidly adherent placenta are associated with higher maternal mortality and morbidity rates. The American College of Obstetrics \& Gynecology (ACOG) committee opinion on placenta accreta provides a review of literature on diagnosis and management of placenta accrete 2012 [10]. Undiagnosed placental abnormalities can present a challenge to small and rural facilities without adequate blood supplies on hand or access to subspecialists required for a complicated accreta delivery. An estimated 7\% of women with placenta accreta die, usually due to hemorrhage [10]. Out of our 125 cases with antepartum hemorrhage, we did not record any maternal mortality. Otherwise than maternal mortality rate, results of our study agreed with the ACOG committee opinion. Results of our study revealed a high morbidity rate in cases with morbidly adherent placenta than cases with Placenta Previa only. The difference between the two groups was statistically significant.

In our study, only $9 \%$ with morbidly adherent placenta was diagnosed prenatally by ultrasound and MRI. In a cohort study in the United Kingdom (UK) analyzing 134 cases with placenta accreta over 1 year study, 50\% of these cases had been suspected by ultrasound in the antenatal period [11].

Our low rate of prenatal diagnosis could be explained by the fact that only $52 \%$ of these cases were booked patients and others were first in emergency labor pains and/or bleeding. Another possibility is a lack of a definite protocol during routine outpatient antenatal ultrasound to select cases that need a more professional, ultrasound or MRI especially for those with previous uterine scar and anterior placenta. Due to small number of prenatally diagnosed cases in our study (1 case), we cannot conclude whether prenatal diagnosis of morbidly adherent placenta can improve the maternal outcome and decrease complications rate. In previous studies, prenatal diagnosis decreased marked complications rate due to multidisciplinary team intervention in these cases [11] [12]. In a previous study, comparing morbidity rates between cases who received the standard obstetric care to that with prenatal diagnosis, thus managed with an ideal precautions and adjusting all needed facilities. Morbidity rates were significantly less in the latter cases. We noticed that apart from estimating the exact amount 
of transfused blood in their study as we are lacking this data in ours and so, we considered the reported hypovolemic shock in the patient's file as a marker of massive transfusion, other parameters of morbidity were more or less similar to ours. It is noticeably evident that our complications rate was very comparable to their recorded ones in the ideal circumstances [13]. This could be attributed to the strict rules in King Abdul-Aziz University Hospital that provide on call consultants in different specialties that can constitute a multidisciplinary emergency team at any time with an available blood bank inside the hospital.

\section{Conclusion}

The present study revealed an increase in the incidence of cases of placenta Previa with concomitant morbidly adherent placenta at King Abdul-Aziz University Hospital. Although we observed a low detection rate of this serious pathology in the prenatal period, it seems that presence of a multidisciplinary team and an available efficient blood bank counteracted the diagnostic pitfalls. A definite screening protocol during antenatal ultrasound is highly recommended to pick up suspicious cases for further confirmation by more professional ultrasound or by MRI if necessary. Whether prenatal diagnosis can further decrease morbidity rates, we cannot conclude an issue due to small number of prenatally diagnosed cases in our study and lack of precise recordings in patients' files. Further multicenter studies are needed to evaluate this.

\section{Conflicts of Interest}

The authors declare no conflicts of interest regarding the publication of this paper.

\section{References}

[1] McShane, P. and Heyl, P. (1985) Maternal and Perinatal Morbidity Resulting from Placenta Previa. Obstetrics \& Gynecology, 65, 176-182.

[2] Chou, M. (2004) Prenatal Diagnosis and Perinatal Management of Placenta Previa Accreta: Past, Present and Future. Taiwanese Journal of Obstetrics and Gynecology, 43, 64-71. https://doi.org/10.1016/S1028-4559(09)60058-9

[3] Heller, D.S. (2013) Placenta Accreta and Percreta. Surgical Pathology, 6, 181-197. https://doi.org/10.1016/j.path.2012.10.003

[4] Frederiksen, F.C., Glassenberg, R. and Stika, C.S. (1999) Placenta Previa: A 22-Year Analysis. American Journal of Obstetrics and Gynecology, 180, 1432-1437. https://doi.org/10.1016/S0002-9378(99)70031-1

[5] Takai, I.U., Sayyadi, B.M. and Galadanci, H.S. (2017) A Retrospective Analysis from a Northern Nigerian Teaching Hospital. International Journal of Applied \& Basic Medical Research, 7, 112-116. https://doi.org/10.4103/2229-516X.205819

[6] Faiz, A.S. and Ananth, C.V. (2003) Etiology and Risk Factors for Placenta Previa: An Overview and Meta-Analysis of Observational Studies. The Journal of Maternal-Fetal \& Neonatal Medicine, 13, 175-190. https://doi.org/10.1080/jmf.13.3.175.190

[7] Abduljabbar, H.S., Bahkali, N.M., Al-Basri, S.F., et al. (2016) Placenta Previa. A 13 
Years' Experience at a Tertiary Care Center in Western Saudi Arabia. Saudi Medical Journal, 37, 762-766. https://doi.org/10.15537/smj.2016.7.13259

[8] Wu, S., Kocherginsky, M. and Hibbard, J. (2005) Abnormal Placentation: Twenty-Year Analysis. American Journal of Obstetrics and Gynecology, 192, 1458-1461. https://doi.org/10.1016/j.ajog.2004.12.074

[9] Kollmann, M., Gaulhofer, J., Lang, U. and Klaritsch, P. (2016) Placenta Praevia: Incidence, Risk Factors and Outcome. The Journal of Maternal-Fetal \& Neonatal Medicine, 29, 1395-1398. https://doi.org/10.3109/14767058.2015.1049152

[10] Committee on Obstetric Practice (2012) Committee Opinion NO. 529: Placenta Accreta. Obstetrics \& Gynecology, 120, 207-211. https://doi.org/10.1097/AOG.0b013e318262e340

[11] Fitzpatrick, K.E., Sellers, S., Spark, P., Kurinczuk, J.J., Brocklehurst, P. and Knight, M. (2014) The Management and Outcomes of Placenta Accreta, Increta, and Percreta in the UK: A Population-Based Descriptive Study. BJOG, 121, 62-71. https://doi.org/10.1111/1471-0528.12405

[12] Silver, R.M., Fox, K.A., Barton, J.R., Abuhamad, A.Z., Simhan, H., Huls, C.K., Belfort, M.A. and Wright, J.D. (2015) Center of Excellence for Placenta Accreta. American Journal of Obstetrics and Gynecology, 212, 561-568.

https://doi.org/10.1016/j.ajog.2014.11.018

[13] Eller, A.G., Bennett, M.A., Sharshiner, M., Masheter, C., Soisson, A.P., Dodson, M. and Silver, R.M. (2015) Maternal Morbidity in Cases of Placenta Accreta Managed by a Multidisciplinary Care Team Compared with Standard Obstetric Care. Obstetrics \& Gynecology, 117, 331-337. 